\title{
JÜRGEN HABERMAS Y CHARLES TAYLOR SOBRE EL PROYECTO DE LA MODERNIDAD
}

\section{JÜRGEN HABERMAS AND CHARLES TAYLOR ABOUT THE PROJECT OF MODERNITY}

\author{
Juan Manuel Cincunegui \\ Universidad del Salvador, Argentina
}

Recibido: 14 de marzo, 2014 • Aceptado: 2 de junio, 2014

\begin{abstract}
Resumen
Los intercambios entre Charles Taylor y Jürgen Habermas en las últimas décadas han sido numerosos. Pese a los numerosos puntos de coincidencia, lo que los distingue, en última instancia, es el modo en el cual cada uno de ellos interpreta el advenimiento de la modernidad occidental. En este artículo damos cuenta de la posición habermasiana sobre este asunto en dos de sus obras capitales, y la crítica que articuló el filósofo canadiense sobre la misma.
\end{abstract}

Palabras clave: Charles Taylor, Jürgen Habermas, Ética, Filosofía política

\begin{abstract}
The exchanges between Charles Taylor and Jürgen Habermas in recent decades have been numerous. Despite the many points of agreement, what distinguishes them is ultimately the way in which each interprets the advent of Western modernity. In this article I consider Habermas's position on this issue and criticism that articulated the Canadian philosopher about it.
\end{abstract}

Keywords: Charles Taylor, Jürgen Habermas, Ethics, Political Philosophy 
E n su obra de 1985 titulada Der Philosophische Diskurs der Modern, Jürgen Habermas ofrece su interpretación de la filosofía que va de Kant a Nietzsche, pasando por Hegel - a quien considera el primer filósofo que desarrolló una comprensión sistemática de la modernidad - y las variaciones que las cuestiones planteadas por estos autores suscitaron, por un lado, en las obras de Heidegger y Derrida; y por el otro, en las de Bataille y Foucault (Habermas, 2008). A su interpretación polémica sobre la filosofía de estos autores, Habermas añade una defensa del contenido de la modernidad (Passerin D'entrèves, 1996).

La disputa de Habermas se dirige contra aquellos que sostienen posiciones en las cuales la modernidad aparece como una era acabada, una era que ha agotado sus proyectos y promesas. Frente a ellos, Habermas adopta una estrategia de defensa que tiene como núcleo argumentativo la convicción de que aun anida en nuestro presente un potencial que da vigencia a los proyectos originales de los maestros ilustrados. Para ello, Habermas retorna de manera concentrada a las consideraciones elaboradas en su Teoría de la acción comunicativa (Habermas, 2001), en donde despliega de manera extensa su teoría de la modernidad y su teoría de la razón comunicativa.

En "Modernidad: un proyecto inacabado" (Habermas, 1988, pp. 265-283), la conferencia que Habermas ofreció con motivo de la aceptación del premio Adorno que se le otorgó en Frankfurt en septiembre de 1980, y que el propio Habermas considera la semilla de las doce lecciones publicadas bajo el título El discurso filosófico de la modernidad, inicia un desarrollo crítico respecto a las corrientes neoconservadoras que habían ido ganando terreno en el debate a partir de la década de 1970 y 1980. Según Habermas, en aquel entonces, se había extendido a todo lo largo y ancho del dominio intelectual una respuesta "afectiva" que había dado lugar a una serie de teorías posilustradas, posmodernas y poshistóricas que, desde su perspectiva, comparten una forma antimodernista. En vista de esto, se propone explorar (1) si la afirmación "posmodernista" del acabamiento de la modernidad puede sostenerse argumentativamente y (2) si acaso eso que llamamos "posmodernidad" no es una parte de la herencia "afectiva" que la modernidad cultural ha provocado como reacción desde mediados del siglo XIX. 
De acuerdo con Habermas, es preciso distinguir, al menos, dos acepciones del término "moderno". Como puede verse incluso en la literatura hegeliana, en la cual Habermas encuentra, como hemos dicho, los desarrollos embrionarios de una teoría de la modernidad bien articulada, el término "moderno" puede ser utilizado para designar (1) la conciencia que posee una época en relación con su pasado - en este sentido, por ejemplo, se utiliza el término "moderno" para designar el presente cristiano oficializado en el siglo $\mathrm{V}$, para distinguirlo del pasado romano-pagano. Pero el término también puede referirse, cuando lo desligamos de su carácter puramente cronológico, a (2) aquello que caracteriza de manera distintiva una época, pero de manera enfática. De esta manera, hablamos de la Edad Moderna a partir de la ruptura que se produce con el Renacimiento, la Reforma y el descubrimiento del "Nuevo Mundo"; pero también podemos hablar de "modernidad" como de aquel período que emerge progresivamente después de aquellos eventos.

Como ha indicado Habermas, citando a Koselleck, la Edad Moderna se caracteriza por ser portadora de una mirada distintiva, "transida de filosofía de la historia". En ella se expresa, nos dice, "un hacerse reflexivamente cargo de la propia posición desde el horizonte de la historia en su conjunto" (Habermas, 2008, p. 16). De este modo, el pasado adquiere para la modernidad la cualidad de historia universal. La actualidad se convierte en un tránsito, que a su vez se consume en la expectativa de lo porvenir. A esta aceleración y simultaneidad cronológica se refieren las expresiones de movimiento que acompañan a la época moderna desde el siglo XVIII: revolución, progreso, emancipación, desarrollo, crisis, etc. (Habermas, 2008, p.17), que a su vez apuntan al hecho de que ahora la modernidad no puede encontrar sus criterios de orientación en el pasado, sino que, a diferencia de otras épocas, está obligada a extraer su normatividad de sí misma. Por lo tanto, nos dice Habermas, la modernidad, en este sentido, se caracteriza: (1) por una conciencia peculiar del tiempo; y (2) por la exigencia de autocercioramiento que trae consigo la transformación de la temporalidad en la conciencia moderna.

El problema de la autojustificación de la modernidad obtiene su primera forma a partir de la mentalidad de la modernidad estética, cuya figura paradigmática es Baudelaire y su teoría del arte, y que posteriormente se despliega en el movimiento de la vanguardia artística, el surrealismo y el Dadaísmo. Se trata, nos dice Habermas, de una conciencia transformada 
del tiempo que nos ayuda a desentrañar su metáfora espacial contenida en el término "vanguardia". "Vanguardia", dice Habermas, se refiere a la exploración de un territorio desconocido, a los riesgos de encuentros imprevistos, a la conquista de un futuro aun indeterminado, y al hecho de que es preciso hallar un camino en un dominio aun no cartografiado (Habermas, 1988, p. 267). Pero la orientación hacia el futuro a la que apunta la vanguardia modernista, tiene como contracara una glorificación de la actualidad. Dice Habermas:

Esta nueva conciencia del tiempo [...] expresa más que la experiencia de la sociedad movilizada, de una historia acelerada, de la ruptura de la vida cotidiana. El nuevo valor concedido ahora a lo efímero, lo momentáneo y transitorio, y la celebración concomitante del dinamismo, expresa, precisamente, el anhelo por un presente duradero e inmaculado. Como un movimiento de autonegación, el modernismo es un "anhelo por la verdadera presencia". Esto, de acuerdo con Octavio Paz, "es el tema secreto de los mejores escritores modernistas (Habermas, 1988, pp. 267-268).

Baudelaire, habla de lo "moderno" como de una composición con dos caras. Una de ellas hace referencia a lo transitorio, a lo fugaz y contingente. La otra, a lo eterno e inmutable. Para Baudelaire, la auténtica obra de arte se encuentra ligada, de manera radical, al instante de su aparición, pero es capaz de colmar el deseo de lo imperecedero conectando lo eterno y lo actual. De esta manera, Baudelaire parece resolver la encrucijada que habían planteado ya los participantes de la celebrada querelle des anciens et des modernes, otorgándole a la actualidad una caracterización doble: el presente, como un relámpago inconsistente, en el seno del cual toman forma las manifestaciones de una belleza auténtica, relativa, pero que en su consumación, da nacimiento a lo que devendrá "clásico".

Sin embargo, el arte vanguardista no debe ser entendido exclusivamente en términos a-históricos. A lo que se opone el modernismo es a la falsa normatividad que ofrece la imitación de los modelos del pasado. Es en esta línea en la que Habermas trae a colación el intento por parte de Walter Benjamín por construir una relación "posthistórica" de la modernidad con la historia, con el fin de escapar a las neutralizaciones que impone al pasado el historicismo. Dice Habermas: 
En este aspecto, para Benjamin el historicismo es simplemente un equivalente funcional de la filosofía de la historia. El historiador que se pone en lugar de todas las épocas y que todo lo entiende reúne la masa de los hechos, esto es, el decurso objetivo de la historia, en una simultaneidad ideal, para llenar con ella "el tiempo homogéneo y vacío (Habermas, 2008, p. 23)².

Ahora bien, en vista, como nos recuerda Habermas, de que las vanguardias de las décadas de 1960 y 1970 - que en buena medida reiteraron los gestos de los movimientos vanguardistas de principio de siglo - estaban dando muestras de cansancio, es necesario (1) determinar la significación de su fracaso y (2) la relación que el fracaso del arte moderno tiene con la propia modernidad, a partir de lo cual podemos (3) determinar el lugar que ocupa en cuanto transición hacia una hipotética posmodernidad.

Es en este contexto en el que se encuadra la crítica de Habermas al neoconservadurismo, y en especial, a la posición articulada por el estadounidense Daniel Bell en The Cultural Contradictions of Capitalism (Bell, 1976). De acuerdo con Bell, bajo interpretación de Habermas, las manifestaciones de crisis que experimentan las sociedades desarrolladas deben atribuirse, fundamentalmente, a la ruptura entre la modernidad cultural y las necesidades del sistema económico y administrativo. La cultura modernista, de acuerdo con Bell, desata una serie de motivaciones hedonistas en los individuos que resultan incompatibles con las exigencias disciplinarias de la vida económica, socavando de este modo el tejido moral de la sociedad. Por lo tanto, desde la perspectiva neoconservadora, es el modernismo, con su empeño en dar prioridad a los principios de autorrealización ilimitada, a la exigencia de autenticidad y al subjetivismo, el que pone en jaque los fundamentos de una vida con objetivos racionales.

1 Sin embargo, a Benjamin le importa no sólo la renovación enfática de una conciencia para la que “cada segundo es una pequeña puerta por la que podría aparecer el Mesías" (tesis 18), sino que, además de proponer su noción de tiempo-ahora, un ahora que lleva incrustadas astillas de tiempo mesiánico o de la consumación del tiempo, se vuelve con desconfianza frente a las actividades apropiadoras del pasado que emprende la actualidad orientada al futuro, con el fin de realizar una drástica inversión. Por un lado, para afirmar que la continuidad de la trama histórica que representa la tradición viene fundada tanto por la barbarie como por la cultura; y por otro lado, "la idea de que cada generación actual no sólo es responsable del destino de las generaciones futuras, sino también del destino que sin merecerlo sufrieron generaciones pasadas (Habermas, 2008, p. 23)". 
De acuerdo con Habermas, la condición para el surgimiento de este tipo de neoconservadurismo la encontramos en la mutación en el uso técnico del término "modernización", el cual, partir de la década de 1950, pasa a referirse a un manojo de procesos acumulativos que se refuerzan mutuamente. Habermas enumera algunos de esos procesos: (1) formación de capital y movilización de recursos; (2) desarrollo de fuerzas productivas e incremento de productividad del trabajo; (3) implantación de poderes políticos centralizados y desarrollo de identidades nacionales; (4) difusión de derechos de participación política, de formas de vida urbana, de educación formal; (5) secularización de los valores y normas. De esta manera, Habermas apunta a la caracterización de la modernización como proceso de operaciones neutrales, es decir, como un proceso que puede "desgajarse de sus orígenes moderno-europeos", como condición para el surgimiento de la "posmodernidad". Dice Habermas:

En vista de una modernización evolutivamente autonomizada, de una modernización que discurre desprendida de sus orígenes, tanto más fácilmente puede el observador científico decir adiós a aquel horizonte conceptual del racionalismo occidental, en que surgió la modernización (Habermas, 2008, p. 13).

De este modo, se contraponen la aceleración de los procesos sociales a una cultura exhausta, lo cual trae como reacción: (1) una apuesta neoconservadora que proclama el advenimiento de la poshistoria y, por ende, la liberación de las dinámicas de la modernización social que se habían visto hasta ahora atadas a una determinada autocomprensión cultural de la modernidad; y (2) una versión antimoderna, "anarquista", que afirma el final de la modernidad en su conjunto.

La posición neoconservadora proclama una versión de la "cultura adversaria" a la que adjudica la responsabilidad de las patologías de nuestro tiempo. A esto suma un diagnóstico que anuncia el final del impulso de la Modernidad, su agotamiento definitivo. Pero como contrapartida, el neoconservadurismo ofrece una serie de mecanismos que cumplen la función de poner limitaciones al libertinaje, con el fin de restablecer las disciplinas y la ética del trabajo. A esto el neoconservador anexa una contraposición entre el Estado social y las virtudes de la competitividad individual. La solución, según este, es una renovación religiosa cuya función es permitir que los individuos reconstruyan identidades claras con garantías existenciales 
como soporte ineludible para el funcionamiento apropiado de los procesos operativos de la modernización (Habermas, 1988, p. 279).

Habermas apunta que el error del neoconservadurismo se encuentra en fundar su interpretación en una inadecuada concepción de la relación entre cultura y sociedad. Esto se pone de manifiesto, especialmente, cuando prestamos atención a la insistencia por parte del neoconservador por atribuir al modernismo las disfuncionalidades y patologías de la modernidad. Lo apropiado en cambio, nos dice Habermas, es reconocer que dichas patologías (hedonismo, narcisismo, atomización social, etc.) y el descontento que provocan (protestas populistas que expresan los temores a la destrucción de los entornos urbanos y naturales, a la destrucción de formas humanas de vida social) son productos derivados que se gestan en la medida del éxito de la economía y la sociedad capitalista. De este modo, dice Habermas:

Este malestar no está provocado por los intelectuales modernistas, sino que tiene sus raíces en las reacciones más fundamentales hacia los procesos de modernización social que, bajo las presiones de sus imperativos de crecimiento económico y la administración del Estado, intervienen de manera creciente en la ecología del desarrollo de las formas de vida social, en la infraestructura de los mundos de la vida históricos (Habermas, 1988, p. 272).

La estrategia de Habermas, por lo tanto, consiste en distinguir la modernización societal de la modernización cultural, lo cual le permite ofrecer un diagnóstico más adecuado de las patologías propias de la esfera cultural. La modernización societal se caracteriza, según Habermas, por la creciente autonomía de los subsistemas de acción racional-instrumental (la economía de mercado y el Estado administrativo) que en su proceso de expansión conducen a una progresiva colonización del mundo de la vida. La modernización cultural, por su parte, se despliega como un proceso creciente de diferenciación de las esferas culturales de valor (ciencia, moralidad y arte), gobernadas por pretensiones de validez distintivas (verdad, justicia y autenticidad) que encarnan diferentes estructuras de racionalidad (cognitivo-instrumental, moral-práctica, estético-expresivo) (Passerin D'entrèves, 1996, p. 3). Ahora bien, en línea con Max Weber, Habermas apunta a la disolución de la unidad de la razón sustantiva expresada por las concepciones religiosas y metafísicas del mundo, que se separan en elementos que ahora 
solo pueden conjugarse formalmente. Esto viene acompañado, a su vez, de una progresiva institucionalización de las competencias de especialistas de los sistemas culturales que abre una brecha cada vez más amplia entre la cultura de los expertos y el gran público. Como consecuencia, la mediación de los expertos acaba empobreciendo la esfera de la vida cuya razón sustantiva fue progresivamente devaluada por la diferenciación cultural.

Sin embargo, como indica Habermas, el proyecto ilustrado, tal como fue formulado en el siglo XVIII combinaba: (1) el desarrollo de objetivación científica, universalización moral y legal, y autonomía del arte, junto a la pretensión de (2) aplicar los potenciales cognitivos liberados en la esfera práctica, con el fin de organizar racionalmente las relaciones sociales. Lo que ahora está en debate no es, ni más ni menos, si esa orientación ilustrada es aun legítima o si acaso es necesario abandonar el proyecto ilustrado en su integridad. Dice Habermas:

La diferenciación creciente de la ciencia, la moral y el arte, con la cual Max Weber caracteriza el racionalismo de la cultura occidental moderna implica, por un lado, el tratamiento especializado de los dominios especiales y su separación respecto a la tradición actual, que continúa fluyendo de manera cuasi natural en el medio hermenéutico de la vida cotidiana. Esta separación es el problema generado por la lógica autónoma de la diferenciación de las esferas de valor. Y es esta separación la que ha provocado los fracasados intentos por "subsumir" las culturas expertas que la acompañan, un fenómeno que se revela más claramente en el dominio del arte (Habermas, 2008, p. 13).

De este modo, la escisión que se produce entre la cultura de expertos y la comprensión cotidiana de los actores no profesionales, acompañada de la progresiva e implacable erosión de las tradiciones, ha provocado ciertas patologías culturales que el propio Habermas describe en términos de "desolación” o "empobrecimiento cultural" (Passerin D'entrèves, 1996, p. 4). El fracaso de la utopía de reconciliación del arte romántico (que también tiene su rastro en Baudelaire), la progresiva reclusión que la autonomía estética produce en relación con el mundo cotidiano, precipitó los intentos violentos por romper la engañosa autarquía de la esfera del arte con el fin de forzar dicha reconciliación. Sin embargo, para Habermas, los intentos por restablecer los lazos entre el arte y la vida, desdibujando los criterios distintivos de la esfera del arte, equiparándolos con las expresiones subjetivas, 
pueden considerarse ahora como experimentos fallidos. A la rebelión surrealista, por ejemplo, puede achacársele un doble error. Por un lado, no haber percibido que el quiebre de la autonomía de la esfera de la cultura conlleva la pérdida de su contenido. Por el otro, teniendo en cuenta que el proceso de comprensión en el mundo de la vida requiere de los recursos de la herencia cultural en su totalidad, aquella no puede ser redimida de su empobrecimiento forzando violentamente un dominio cultural con el fin de establecer conexiones con otro dominio especializado de conocimiento. Dice Habermas:

Una vez la praxis de la vida cotidiana, orientada como está hacia el juego sin restricciones entre las dimensiones de lo cognitivo, lo moral-práctico y lo estético-expresivo, se ha reificado, no puede ser remediada conectándola con alguno de los dominios culturales abiertos a la fuerza (Habermas, 1988, p. 278).

De allí se desprende que, para Habermas, las distorsiones que han acompañado al proyecto de la modernidad junto a las equivocadas propuestas para subsumirlas, deben servir para aprender una escapatoria de las aporías, en contraposición con la apuesta neoconservadora y anarquista posmoderna de abandonar el proyecto ilustrado en su integridad. Como ocurre cuando el contenido del dominio autónomo del arte es incorporado en la historia individual o en una forma de vida colectiva cambiando su carácter funcional al relacionarse con los problemas de la vida o siendo utilizado para iluminar una situación histórica determinada, el contenido abstracto de las esferas de la ciencia y la moralidad exigen una reconexión con aquellos problemas que conciernen a la vida buena, de los cuales fueron inicialmente excluidos.

De acuerdo con Habermas, para comprender el clima de opinión antimodernista que reina en el mundo occidental, promovido por una variedad de posiciones conservadoras, es necesario regresar a Hegel que, como ya indicamos, es quien inaugura el discurso de la modernidad. La razón de ese privilegio, según Habermas, es que en Hegel se problematiza por vez primera el "desgajamiento y ruptura de la modernidad respecto de las sugerencias de normatividad del pasado" (Habermas, 2008, p. 23). En buena medida, la filosofía hegeliana puede entenderse a partir de la necesidad que 
tiene la modernidad, en su desasosiego, de lograr estabilizarse a sí misma una vez abandonados los modelos del pasado.

Para Hegel el principio original de la Edad Moderna es la subjetividad, asociada (1) al individualismo, la competencia crítico-racional y la autonomía práctica; y entendida en última instancia (2) como principio de determinación de las manifestaciones de la cultura moderna: ciencia objetivante, conceptos morales definidos a partir del reconocimiento de la libertad subjetiva de los individuos y arte moderno determinado por la interioridad absoluta. De este modo, nos dice Habermas, "en la modernidad, la vida religiosa, el Estado y la sociedad, así como la ciencia, la moral y el arte, se convierten en otras tantas encarnaciones del principio de la subjetividad" (Habermas, 2008, p. 29).

Pese a que Hegel - de acuerdo con Habermas - reconoce en la filosofía kantiana, de manera concentrada, la esencia del mundo moderno, advierte en ella una ausencia de problematización que marca al proyecto con una ambigüedad. La filosofía kantiana funda los dominios separados de la ciencia, la moralidad y el arte en la subjetividad, pero como indica Hegel, la remoción de la racionalidad sustantiva por la noción de racionalidad diferenciada y unificada formalmente no viene acompañada de una problematización explícita de la necesidad de una síntesis entre las diversas esferas de la razón. Para Hegel, sin abandonar el proyecto ilustrado, la cuestión gira en torno a que el principio de la subjetividad y la autoconciencia subyacente puedan o no estabilizar una formación histórica que se funda en una ruptura con la tradición. Se trata, según Fred Dallmayr (Dallmayr, 1996, p. 60), de encontrar una síntesis racional que pueda reconciliar los aspectos escindidos de la razón moderna con el fin de restaurar la integridad de la vida ética, es decir, reconciliar las dicotomías que la filosofía kantiana (y fichteana) "establecen entre naturaleza y espíritu, sensibilidad y entendimiento, entendimiento y razón, razón teórica y razón práctica, juicio e imaginación, yo y no-yo, finito e infinito, saber y creer" (Habermas, 2008, p. 32). Sin embargo, debido a las ataduras subjetivistas de las cuales Hegel no puede escapar y el exagerado carácter contemplativo de su propuesta, Habermas concluye sentenciando el fracaso del proyecto hegeliano.

Entre los escritos de juventud de Hegel, Habermas reconoce dos intentos por superar el carácter ambiguo que anida en la formulación kantiana. En el primero de dichos programas, formulado en su época de Tübingen, junto a Hölderlin y Schelling, Hegel ofrece una versión romántica o 
mitopoética de reconciliación que se opone de igual modo a (1) la ortodoxia positiva de la religión que se funda en la autoridad y pone el valor del hombre en la moral de dicha autoridad; y (2) a la religión racional pura, caracterizada por su abstracción, "que resulta incapaz de interesar el corazón del hombre e influir sobre sus sentimientos y necesidades" (Habermas, 2008 , p. 38). En contrapartida, Hegel propone restablecer un lazo ético de reconciliación entre los diversos elementos en conflicto de la vida social moderna. Como señala Habermas, en sus primeros escritos Hegel insiste en que la reconciliación no puede derivarse de la subjetividad, señalando el carácter autoritario de la autoconciencia:

La positividad de la religión contemporánea, que viene provocada a la vez que afianzada por la ilustración, al igual que el positivismo ético en general, caracterizan "la penuria de la época", y en "en la penuria, o bien el hombre es convertido en objeto oprimido, o bien tiene que convertir en objeto y oprimir a la naturaleza". Este carácter represivo de la razón se funda en términos generales en la estructura de la relación del sujeto consigo mismo, es decir, en la relación de un sujeto que se torna objeto de sí mismo (Habermas, 2008, p. 40).

Es en este contexto en el que Hegel propone una reconciliación ética. Para Hegel, ético, en contraposición a moral, es "un estado social en que a todos los miembros les son reconocidos sus derechos y todos satisfacen sus necesidades sin necesidad de vulnerar los intereses de los otros" (Habermas, 2008, p. 40), una reconciliación que brota de la "añoranza por la vida perdida" que obliga a los implicados "a reconocer la existencia del prójimo, objeto de represión, la negación de la naturaleza propia” (Habermas, 2008, p. 41). Como señala Habermas, lo que Hegel opone a las leyes abstractas de la moral es un tipo de legalidad totalmente distinta que caracteriza la culpa, surgida de la ruptura de una totalidad ética presupuesta, "la perturbación de las condiciones de simetría y reconocimiento recíproco en un contexto de vida constituido intersubjetivamente, del que una de las partes se aísla extrañándose de las otras y de la vida en común” (Habermas, 2008, p. 41).

Habermas advierte, sin embargo, que la conexión entre la religión civil y el nexo de culpa se apoya en formas de vida premodernas que el proceso de modernización obliga a dejar atrás. Los presupuestos de Hegel - según Habermas - son las condiciones de un pasado idealizado: el de las comunidades cristianas tempranas y el de la polis griega. 
Por otro lado, en el "Espíritu del cristianismo y su destino", también bajo la influencia de Schelling y Hölderlin, Hegel concede al arte la función reconciliadora, como elemento que convierte la religión abstracta de la Ilustración en religión popular. Sin embargo, Habermas reconoce que Hegel rápidamente abandona, por inadecuado, este proyecto. La razón reside en que, para hacer frente a la modernidad, cuyo principio rector es la subjetividad y el poder de la reflexión crítica, es necesaria la razón filosófica. Es decir, frente al desafío que significa para la filosofía una modernidad orientada decididamente hacia el futuro, Hegel opta por regresar a la única fuente de normatividad que tiene a su disposición, aquella que brota de la propia conciencia histórica de la modernidad, el principio de la subjetividad. Hegel es consciente de la negatividad de una facultad de reflexión vuelta sobre sí, autonomizada, transformada en absoluto. Por esa razón, se ve obligado a ampliar el intelecto (Verstand) como único vínculo que la modernidad debe reconocer a la Razón (Vernunft), "siguiendo los rastros de una dialéctica de la ilustración” (Habermas, 2008, p. 54). Dice Habermas:

Pero al elevarse a saber absoluto la razón acaba adoptando una forma tan avasalladora, que no solamente resuelve el problema inicial de un autocercioramiento de la modernidad sino que lo resuelve demasiado bien: la pregunta por la genuina autocomprensión de la modernidad se desvanece en una irónica carcajada de la razón. Pues la razón ocupa ahora el lugar de un destino y sabe que todo acontecer que pueda tener algún significado esencial está ya decidido (Habermas, 2008, p. 54).

Esto trae como consecuencia una devaluación de la actualidad y una neutralización de la crítica. La filosofía se ve privada de "instruir al mundo acerca de cómo debe ser" (Habermas, 2008, p. 55), puesto que sus conceptos sólo reflejan la realidad tal cual es. Eso significa que la filosofía ya no está obligada a confrontar la "existencia mala de la vida política y social con su concepto" (Habermas, 2008, p. 55). Dice Habermas:

Hegel no es el primer filósofo que pertenece a la época moderna, pero es el primero para el que la modernidad se torna problema. En su teoría se hace por primera vez visible la constelación conceptual entre modernidad, conciencia de tiempo y racionalidad. Hegel acaba rompiendo esta constelación porque la racionalidad levantada a espíritu absoluto neutraliza las condiciones bajo 
las que la modernidad cobró conciencia de sí misma. Pero con ello Hegel no solventó el problema de la autocercioramiento de la modernidad. Para la época que sigue a Hegel, la moraleja de todo ello es que para poder en general tener la posibilidad de seguir elaborando este tema es menester articular el concepto de razón en términos mucho más modestos (Habermas, 2008, p. 56).

La filosofía de Hegel tiene un carácter paradigmático para el pensamiento contemporáneo. En la narración que Habermas realiza sobre el discurso filosófico de la modernidad, ocupa el lugar central. Es la fuente última a partir de la cual fluye cierto "ánimo" filosófico de la contemporaneidad. En ella se otorga un nuevo rango al momento histórico que trastocó de manera radical el carácter de la filosofía convirtiéndola en revolucionaria. Por otro lado, Hegel impone a la filosofía posterior una noción de acabamiento de sí que está en acuerdo con esa "ruptura revolucionaria" con la tradición que "se produjo cuando el espíritu de la época cobró poder sobre la filosofía” (Habermas, 2008, p. 64).

La suerte de la filosofía contemporánea sigue gravitando alrededor de la primera reacción que introdujeron los jóvenes hegelianos al distanciarse de Hegel y la filosofía en general. Ellos fueron los que asentaron de manera duradera, dice Habermas, lo que Hegel había introducido en el discurso. Los jóvenes hegelianos se enfrentaron a la marginación de lo meramente empírico, de la existencia contingente, que había realizado Hegel con la articulación de su concepto de realidad como unidad de la esencia y la existencia. En contrapartida, los jóvenes hegelianos reclaman el peso de la existencia, un regreso a la facticidad. Todos ellos convienen: (1) sobre el carácter ilusivo de cierta dimensión del proyecto ilustrado; y (2) sobre la existencia de rasgos autoritarios que tienen su origen en la estrechez que la adhesión al principio de la autoconciencia trae consigo: el sujeto ilustrado se realiza por medio del conocimiento y la acción de su interioridad y su exterioridad por medio de la objetivación. Dice Habermas:

En la discusión acerca de la modernidad los acusadores hacen una objeción que en sustancia no ha cambiado desde Hegel y Marx hasta Nietzsche, Heidegger, desde Bataille y Lacan hasta Foucault y Derrida. La acusación es contra una razón que se funda en el principio de la subjetividad y dice que esta razón sólo denuncia y socava todas las formas abiertas de represión y explotación, de humillación y extrañamiento, para implantar en su lugar 
la dominación inatacable de la racionalidad misma [...] Todos los partidos están de acuerdo en una cosa: hay que hacer añicos esa fachada de vidrio. Sin embargo, se distinguen en las estrategias que escogen para superar el positivismo de la razón (Habermas, 2008, p. 68).

Habermas considera - en consonancia con todos estos críticos - que se ha producido un agotamiento del paradigma inicial de la modernidad, aquel que se encuentra basado, justamente, en la afirmación de un sujeto que intenta encontrar a partir de sí mismo y en la propia razón sus criterios de justificación. Su narración pretende demostrar, de una manera u otra, que las apuestas reactivas que después de Hegel desplegó la filosofía contemporánea, siguen atadas al tan denostado principio de la autoconciencia. Su propósito es mostrar de qué manera es posible rearticular la modernidad a partir de un giro pragmático-lingüístico que ofrezca ocasión para establecer un nuevo fundamento, esta vez procedimental, para el despliegue de una razón comunicativa. De este modo, la estrategia habermasiana será, en primer lugar, decididamente defensiva, dirigida a refutar a aquellos empeñados, por muy diversas razones, en la liquidación de la modernidad, articulando posiciones antimodernas, premodernas y posmodernas.

En "Modernidad: un proyecto inacabado" (Habermas, 1988, pp. 282 3), Habermas reconoce en los "Conservadores antiguos" el rechazo de la modernidad cultural en su integridad. Estos juzgan con desconfianza, por un lado, la razón sustantiva y la diferenciación progresiva de las esferas de la ciencia, la moral y el arte; por el otro, se oponen a la comprensión moderna del mundo y a los cánones procedimentales de la racionalidad. Para los adherentes de esta corriente, la respuesta a los malestares de la modernidad consiste en regresar a las posiciones premodernas. Habermas identifica entre los "Conservadores antiguos" a los adherentes del neoaristotelismo contemporáneo y aquellas filosofías que han encontrado asimiento en cuestiones ecológicas, renovando la idea de una "ética ecológica".

Los llamados "Neo-Conservadores" son aquellos asociados decididamente a los logros de la ciencia moderna, la promoción tecnológica, el desarrollo capitalista y las formas racionales de administración. Esta asociación es a su vez acompañada por una política dirigida a desactivar los elementos explosivos de la modernidad cultural. Este desgajamiento entre los elementos operacionales hipotéticamente neutrales de la modernización y la dimensión cultural adquiere, de acuerdo con Habermas, diversas formas. Una posición 
afirma que la ciencia, cuando es comprendida cabalmente, se vuelve insignificante en lo que respecta al mundo de la vida (un ejemplo de ello es la filosofía del primer Wittgenstein). Otra posición aboga por la inmunización de la política frente a las demandas de legitimación práctico-morales (la posición del período medio de Carl Schmitt es un ejemplo de ello). Finalmente tenemos el caso de aquellos que afirman la inmanencia total del arte, oponiéndose de este modo a la idea de su contenido utópico, con el fin de confinar la experiencia estética en la esfera privada (la época tardía de Gottfried Benn ilustra esta posición).

Finalmente, Habermas reconoce en los Jóvenes Conservadores, la adopción de una posición en la cual la experiencia estética de la modernidad se opone dialécticamente a la razón instrumental. Se trata, nos dice Habermas, de hacer de la subjetividad liberada de todos los constreñimientos de la acción cognitiva e instrumental y los imperativos del trabajo y el valor de uso, el eje de ruptura con el mundo moderno. Nietzsche, quien se opuso a los intentos de los hegelianos de izquierda y de derecha, partidarios de la revolución y la reacción respectivamente, es el paradigma de estos pensadores. Él se impuso la tarea de desenmascarar la dramaturgia revolucionaria y reaccionaria acusando a la razón de no ser otra cosa que poder (Habermas, 2008, p. 51). La tradición francesa de Bataille, Foucault y Derrida ejemplifica este tipo de conservadurismo.

\section{II}

Hasta aquí hemos abordado el tratamiento crítico que hace Habermas respecto a la problemática de la modernidad en El discurso filosófico de la modernidad y otros textos afines. A continuación, a través del análisis que Taylor realiza sobre La Teoría de la acción comunicativa, abordaremos su "otra manera para escapar - según sus propias palabras - a la filosofía del sujeto" ${ }^{2}$. Su posición se articula a partir de una reelaboración de la teoría social a la luz de la filosofía del lenguaje. De acuerdo con Taylor, una de las líneas argumentativas centrales del texto en cuestión consiste en un despliegue de la teoría social que tiene como fundamento un desplazamiento

2 "Otra manera de salir de la filosofía del sujeto: razón comunicativa versus razón centrada en el sujeto" es el título de la onceava lección de El discurso filosófico de la modernidad donde Habermas despliega de manera concentrada el giro pragmático-lingüístico que caracteriza su teoría social. 
desde la perspectiva fundacional de la subjetividad que subyace a la teoría social en general, a una comprensión que se justifica a partir de la filosofía del lenguaje, que a su vez se aborda a partir de las estructuras del discurso.

En primer lugar, Taylor señala que Habermas defiende una aproximación fundamentalista del lenguaje en la que este se concibe desarrollándose y renovándose en el discurso. De acuerdo con Taylor, en la misma línea que recorrieron autores expresivistas como Herder y Humboldt, Habermas defiende que la adquisición de la habilidad del habla se desarrolla exclusivamente con la condición de la participación del agente en el discurso. Esto tiene importantes consecuencias en lo que respecta a la teoría social. Por ejemplo, Taylor considera que las concepciones atomistas de la sociedad, del tipo de aquellas adelantadas en su momento por Hobbes y Locke, que en términos generales pretenden una explicación genética de lo social a partir de las acciones y acuerdos de los individuos, se vuelven inaceptables. Y esto debido a que la noción de individuo, desde esta perspectiva, presupone necesariamente la noción de comunidad. Es decir, supone un marco de acuerdos y normas dentro del cual los individuos actúan. Esto significa, en definitiva, que la teoría social no puede articularse exclusivamente a partir de la actividad de los individuos, sino que debe dar cuenta, en primer término, del marco comunitario sobre el cual se construye la significación de los actos individuales.

Por otro lado, Taylor apunta a que en la obra de Habermas hay una referencia explícita a lo que él llama el "principio de complementariedad entre estructura y práctica" (principio de complementariedad E/P). Para explicar dicho principio, Taylor nos recuerda un fenómeno análogo descrito por Sausurre. Se trata del uso que hace el lingüista francés de los términos "langue" y "parole". La relación entre estos dos extremos es análoga a la relación recíproca que se establece entre la estructura y la práctica. Aquí la estructura hace referencia al aspecto normativo de los actos de habla. Las acciones del agente no crean la estructura de sus propios actos de habla. Por el contrario, cada uno de estos actos de habla presupone constitutivamente dicha estructura. Sin embargo, de esto no se debe inferir que la estructura exista independientemente de las prácticas de los hablantes. Todo lo contrario, la estructura depende de dichos actos para reproducirse a sí misma. Por lo tanto, una consecuencia inmediata de la afirmación del principio de complementariedad $\mathrm{E} / \mathrm{P}$ es que refuta las teorías monistas del lenguaje. 
De acuerdo con Taylor, la enunciación de este principio indica otra faceta importante en la teoría social de Habermas. A diferencia de lo que ocurre con algunos autores que se adhieren a la tesis fundamentalista del lenguaje pero ignoran el principio de complementariedad E/P otorgándole de este modo primacía absoluta a la sociedad por sobre el individuo, Habermas señala que el abandono de la filosofía de la conciencia nos fuerza a reconocer la relevancia de la socialización que se realiza sobre los individuos pero siempre en el contexto de un proceso de continua renovación de la propia tradición social realizada por los mismos individuos. Esto ocurre cuando se produce un desplazamiento desde las nociones que aun gravitan en la esfera de la conciencia hacia la filosofía del lenguaje, porque en el primer caso, podríamos hablar de una teoría de internalización para la cual las normas y acuerdos de la sociedad son impresas en la conciencia de los individuos en la manera de "representaciones colectivas" a través del proceso de socialización.

En tercer lugar, como consecuencia de la relación correlativa E/P, Habermas formula el principio de significación del "trasfondo de conocimiento". Este principio previene la pretensión de que el código o estructura subyacente a las prácticas existe de manera íntegra antes de ser articulada en las prácticas concretas. Las prácticas lingüísticas, nos dice Taylor, no solo se mueven sobre el marco estructural de un código, sino que se basan en nuestras habilidades prácticas y pre comprensiones. Esto tiene consecuencias para la teoría social. De acuerdo con Taylor, además de las costumbres y normas articuladas, las prácticas sociales se basan en un trasfondo inagotable e inarticulado desde donde surgen las innovaciones. Lo cual supone para la teoría social la necesidad de desarrollar dos niveles de explicación: (1) Una explicación cuyo objeto sea el nivel estructural; acompañada de (2) un suplemento de referencias a los contextos de acción.

Taylor considera dos consecuencias inmediatas para la teoría social en relación con el principio de complementariedad E/P:

(1) Desde la perspectiva del observador resulta tentador problematizar la teoría tomando en consideración que, para dar cuenta de las acciones de los participantes, el observador debe articular elementos del trasfondo que resultan implícitos para los participantes. Sin embargo, la tentación puede ser rechazada sobre la base de las consideraciones anteriores respecto a la naturaleza del trasfondo, en cuanto las 
explicaciones del observador, si son ajustadas, responden a las que los propios participantes adoptarían si adquirieran una comprensión más acabada de sí mismos.

(2) Por otro lado, la significación del trasfondo pone en entredicho los intentos por explicar la sociedad a partir de modelos computarizados debido a la formalización exhaustiva de su funcionamiento. La actividad de los agentes reales siempre involucra componentes no formulados. La práctica humana es una estructura que rebasa las conexiones formales, las cuales tienen en la actividad de los agentes una función muy limitada.

Finalmente, Taylor enfatiza en el argumento de Habermas la adhesión de este al principio de complementariedad del "yo" y el "nosotros". Dice Taylor:

En el discurso nosotros hablamos sobre algo. Eso significa, sin embargo, que la cuestión que planteamos existe no sólo para mí o para usted, sino para nosotros. Cuando inicialmente nos ocupamos en el discurso abrimos, por así decirlo, un espacio referencial común. Lo que es de interés entonces es la relación entre la postura del nosotros y la perspectiva del yo de los participantes (Taylor, 1991, p. 27).

Esto tiene especial relevancia si tomamos en consideración la orientación literal que compartimos en el espacio. En este debemos conocer las diferentes ubicaciones de los participantes espacialmente, así como descubrir el modo en el cual nos orientamos en el mismo. En este sentido, Taylor identifica dos tipos de expresiones referenciales: (1) las descripciones geográficas y (2) las expresiones deícticas que son utilizadas exclusivamente en relación a la perspectiva de los hablantes. Estos dos tipos de expresiones deben estar siempre coordinadas.

De manera análoga, las perspectivas del nosotros y la perspectiva del yo en el discurso tienen una relación complementaria. La perspectiva del nosotros es originaria, lo cual implica que no puede ser interpretada a partir de las perspectivas individuales de manera acumulativa. Pero al mismo tiempo, la perspectiva del yo no es prescindible, porque es constitutiva para la participación del hablante en la constitución del nosotros. En los casos normales, nos dice Taylor, la perspectiva del nosotros requiere, al 
menos, una comprensión implícita de la perspectiva del yo, que el hablante adquiere a través de un proceso ontogenético que desemboca en la comunicación normal entre adultos que necesita para su pleno despliegue la diferenciación e interconexión entre los dos niveles.

Ahora bien, es sobre la base de esta concepción de la estructura del discurso que Habermas pretende clarificar la especificidad de la acción social. Originalmente, nos dice, los participantes actúan en determinado acto social desde la perspectiva del "Nosotros", siguiendo reglas y aplicando normas aceptadas implícitamente por todos, como ocurre, por ejemplo, con una danza ritual africana. Pero puede ocurrir que la perspectiva del nosotros se ponga en cuestión. Esto sucede cuando se produce una ruptura en la comprensión que tenemos del "espacio común" de las normas. En este caso, lo que ocurre es que se produce una interrupción en la correlación entre las perspectivas del yo y del nosotros.

Para Habermas, la recomposición de esta correlación no puede realizarse, como dijimos, por medio de una estrategia de síntesis acumulativa de las perspectivas del yo. La existencia de una perspectiva individual supone como condición constitutiva la existencia de una perspectiva del nosotros. El consenso dirigido a la reparación de la perspectiva colectiva dañada sólo puede ocurrir sobre la base de algo que compartan los individuos ante de su "atomización". Para Habermas, la incrustación de cada individuo en una perspectiva aun más general de normas compartidas que actúan como trasfondo de conocimiento común es lo que permite la reconstitución de la perspectiva dañada. Eso conlleva la labor de encontrar "razones" para el consenso dentro de un horizonte que sea aceptable para todos los participantes en el debate.

De acuerdo con Taylor, la teoría de la sociedad de Habermas tiene la virtud de permitir una transformación de la teoría social que tome en consideración la semejanza entre la estructura de la acción y la del discurso. Por otro lado, permite abordar la crisis de las sociedades del capitalismo tardío de modo renovado. Dice Taylor:

De acuerdo con Habermas, hoy día nos enfrentamos no sólo a la represión intelectual de la teoría de sistemas sobre la estructura discursiva de la vida social, sino también a la represión real de los procesos para el logro de entendimiento en favor de formas sistémicas de integración como el mercado y el Estado burocrático que, hasta cierto punto, funcionan de espaldas a los participantes y alcanzan sus propósitos dirigiendo los mecanismos (Taylor, 1991, p. 29). 
Para Habermas las experiencias de pérdida de libertad y sentido que se manifiestan en la actualidad encuentran su origen, precisamente, en este tipo de represión sobre los procesos de comprensión mutua de los participantes, pero no deben ser interpretados como el resultado irreparable de los procesos de modernización. Habermas responde a aquellos que sostienen que estas experiencias son el resultado ineludible al que nos aboca la disolución de las cosmovisiones premodernas de origen religioso o metafísico, señalando que es posible reemplazar dichas cosmovisiones por procesos de comprensión mutua que permanezcan libres de los mecanismos de dominación. De este modo, Habermas atribuye al dominio de los sistemas no significativos las experiencias de pérdida de sentido que caracterizan a las sociedades del capitalismo tardío.

Ahora bien, la crítica de Taylor a la posición de Habermas gira en torno a dos ejes:

1. Respecto a la decisión subyacente por parte de Habermas por articular una ética exclusivamente procedimental.

2. Respecto a la manera en la cual Habermas incorpora el enunciado weberiano sobre la tridimensionalidad de la racionalidad.

Con respecto al primer punto, Taylor sostiene que Habermas se restringe exclusivamente a los elementos que le ofrece una ética formal de la racionalidad, cuyo ejemplo paradigmático lo encontramos en Kant, para quien la determinación de la buena vida no se realiza en términos de su contenido - un tipo de vida a ser realizada - sino más bien a la determinación de la acción correcta sobre la base de procesos procedimentales de decisión respecto al deber ser. En contraposición, Taylor aboga por una ética sustancialista a la que, de nuevo, de manera paradigmática ilustra con la filosofía aristotélica, que procede a partir de una noción de la vida buena. Para Taylor, la distinción entre éticas substantivas y éticas procedimentales se deriva del uso distintivo que hacen las diversas formas de teoría ética de la noción de racionalidad. En el caso de las éticas sustantivas, como ocurre con Platón o Aristóteles, la racionalidad se identifica con una comprensión correcta. En este sentido, no puede adjudicársele racionalidad a un agente que se adhiere, por ejemplo, a la concepción de Demócrito sobre el mundo natural o a la concepción de que la mejor vida es aquella dispuesta a la satisfacción de los deseos sensuales. Por otro lado, una concepción 
procedimental de la racionalidad, como ocurre con Descartes o Kant, rompe esta comprensión. La racionalidad o pensamiento de un agente, nos dice Taylor, se juzga por cómo piensa, no a partir de la corrección sustantiva del resultado. En el caso de Aristóteles, por ejemplo, se trataba de tener la visión correcta, o, en el caso de la phronêsis, de lo que se trata es de una certera capacidad de discriminación moral. Para los Kantianos, en cambio, una vez hemos dejado al margen el sentido o visión del bien, lo que cuenta como procedimiento definitivo de la razón práctica es la universalización (Taylor, 1989, pp. 85-6). En el caso de Habermas, se trata de identificar un conjunto de cuestiones que atañen a la justicia universal, es decir, a la aceptabilidad universal de las normas que delimitan el ámbito de la ética discursiva otorgándoles un estatuto superior al de las cuestiones concernientes a la vida mejor y más satisfactoria, restringiendo de este modo la extensión de lo "moral" en relación con la concepción a la que se adherían los filósofos antiguos cuando hablaban de ética (Taylor, 1989, p. 64).

Taylor reconoce que la ética procedimental ofrece buenas razones a sus adherentes, en cuanto (1) evita los problemas epistemológicos que trae consigo la pretensión de determinación de la vida buena; (2) ofrece un concepto de libertad más radical que el que propone la ética sustancial y (3) es capaz de mantener una distancia plena con las formas culturales específicas de vida. En contraposición la ética sustancialista se encuentra siempre ligada a los ideales y valores de una cultura particular y por ello, más o menos cerrada a otras formas culturales (Taylor, 1991, p. 30).

Pero, pese al atractivo que manifiestan las éticas procedimentales, Taylor encuentra inconsistente la adscripción exclusiva a las mismas. Esto se pone de manifiesto cuando nos enfrentamos al problema de la justificación. Pensemos en el caso de Kant. La solución que ofrece a la cuestión de la justificación de la obligación racional escapa al ámbito meramente procedimental para adentrarse en la esfera sustancialista de la ética. Interrogado el agente acerca del porqué de su adhesión a una moral de obligación, su respuesta sólo puede articularse en el ámbito de las evaluaciones fuertes. En el caso concreto de Kant, el agente es llamado a reconocer que la obligación reposa, en última instancia, en la dignidad propia (un concepto sustancialista) que lo mueve a actuar de acuerdo con su naturaleza racional.

Aun así, Habermas insiste en desarrollar una ética exclusivamente procedimental. El principio de fondo es el logro de entendimiento racional. El modo en el cual accedemos a ese entendimiento es a través del 
reemplazo de mecanismos no racionales de acción coordinada por formas racionales para alcanzar entendimiento. Pero el problema de justificación sigue en pie: ¿Por qué razón - se pregunta Taylor - debería preferir la comprensión racional? ¿Por qué debería tener este tipo de propósito una posición privilegiada para mí? ¿Por qué razón debo privarme de lograr mis propósitos deseados pese a resultar más o menos inconsistente? (Taylor, 1989, p. 31).

Lo que Taylor pretende con estas preguntas es demostrar que los interrogantes en torno a la justificación última de nuestras acciones se realizan en un nivel diferente al de la ética procedimental. La respuesta a dichas preguntas sólo puede articularse sobre la base de nuestra adscripción a un determinado concepto de la vida humana que nos permita ubicar la comprensión racional en un lugar privilegiado. Eso significa que, en última instancia, no podemos evadir una posición sustancialista de la ética.

Y esto es especialmente relevante en el caso de la propuesta habermasiana. De acuerdo con su descripción de las sociedades del capitalismo tardío, Habermas aboga por una defensa del mundo de la vida frente a la colonización que éste sufre por la presión que le imponen los órdenes sistémicos de la empresa corporativa y la burocracia, con el fin - nos dice - de crear un espacio para el despliegue de los procesos para alcanzar entendimiento racional. El problema, de acuerdo con Taylor, es que un proyecto de este tipo requiere una poderosa justificación que Habermas parece no estar en disposición de ofrecer si se empeña en la articulación de una ética exclusivamente procedimental.

Taylor ofrece dos argumentos contra la posición de Habermas. En primer lugar, sostiene que lo que permite la adscripción a la posición habermasiana es cierta comprensión no necesariamente tematizada de la naturaleza humana que está en línea con la antigua definición aristotélica del anthropos como zoon echon logon. Sin embargo, una definición de este tipo necesita para nosotros de una reinterpretación en clave expresivista, es decir, una teoría sustancialista del carácter constitutivo del lenguaje para la definición del anthropos. En segundo término, Taylor señala que el principio fundamental de comprensión racional no puede dirimir todas las cuestiones de evaluación fuerte. Existen otras cuestiones, como la cuestión ecológica, que no pueden ser definidas en términos exclusivamente procedimentales sino que, por el contrario, requieren determinaciones sustancialistas respecto a la constitución de la vida buena para ser resueltas. 
Frente a esto, Habermas se ve obligado a distinguir los órdenes del discurso apuntando que solo aquellas cuestiones que son resueltas sobre la base de un criterio universal para alcanzar comprensión racional son cuestiones morales, mientras que el resto pertenecen al orden de comprensión local de significación de la vida buena. El problema, sin embargo, es que las cuestiones morales a las que hace referencia Habermas y las cuestiones sustanciales respecto a lo que significa una vida buena se encuentran inextricablemente conectadas. Taylor cree que el intento por establecer una delimitación férrea entre las cuestiones de justicia y las cuestiones sobre la vida buena es consecuencia de una decisión a priori que opta por una ética procedimental.

El segundo punto que anunciamos hacía referencia a la adopción no cuestionada por parte de Habermas de la distinción weberiana de las tres dimensiones de la racionalidad. De acuerdo con Habermas, el diagnóstico que Weber llevó a cabo sobre su época tiene tanta actualidad como cuando fue presentado por primera vez. John Sitton sostiene que la explicación de Weber de la racionalización cultural y social es el punto de arranque de la teoría social de Habermas en tres importantes aspectos. Por un lado, Habermas interpreta la expresión de Weber "jaula de hierro" mediante la cual éste hacía referencia al aspecto "reprobable" o "perverso" que el predominio material tiene en la vida contemporánea a la luz de la perspectiva precapitalista, como una pérdida de libertad que produce la imposición de los sistemas de organización de la economía capitalista y la burocracia. En segundo término, Habermas se adhiere a la convicción de Weber de que el origen de la "pérdida de sentido" se encuentra en el surgimiento de las esferas de valor independiente y de órdenes de vida que se "cristalizan" en torno a ellas. A esto suma Habermas las rupturas de la vida social causadas por la expansión de las redes económicas y burocráticas. Finalmente, Habermas comparte la idea weberiana de que el desarrollo cultural se encuentra separado del cambio social (Sitton, 2003, pp. 19-21).

En la época premoderna las cuestiones acerca de la verdad, la corrección y la autenticidad personal se encontraban inextricablemente relacionadas. Desde la perspectiva platónica, por ejemplo, las cuestiones normativas se resolvían mediante un concepto cosmológico de orden. La modernidad trajo consigo una diferenciación relativa de estas áreas, lo cual se tradujo en la concesión a las ciencias en general, y en particular las ciencias naturales, de un estatuto diferente al que se le otorga a la esfera que se refiere a las cuestiones de realización personal, por ejemplo. Todo esto, nos 
dice Taylor, es más o menos evidente. Sin embargo, Habermas pretende que la modernidad consiste justamente en la separación de estos dominios de racionalidad hasta el punto de que las cuestiones surgidas en cada una de estas áreas independientes deben ser resueltas sobre la base de sus respectivos criterios racionales de justificación.

Lo que subyace a esta interpretación es: (1) que la modernidad de hecho trata de manera creciente cuestiones de verdad, corrección y autenticidad como si cada una de ellas aplicara una lógica independiente en su propia esfera y (2) que esta diferenciación constituye un progreso, en cuanto resuelve con mayor efectividad la problemática de validez particular en cada una de estas esferas. De esto se sigue, nos dice Taylor, (3) que es posible resolver las cuestiones de la ética formal independientemente de las cuestiones referidas a la verdad. Pero a esto responde Taylor:

Las dos vertientes de la proposición [...] están abiertas a cuestionamiento. De hecho nuestra razón práctica no procede formalmente para conocer cuáles son nuestros deberes sobre la base de un criterio procedimental. Más bien, inicialmente reconocemos diferentes propósitos de vida o virtudes, entre los cuales desempeñan un papel central la sensatez, la justicia, la caridad, y nos esforzamos por combinar todos ellos en el punto correcto y en una relación adecuada entre sí en esta vida que tenemos (Taylor, 1989, p. 33).

De este modo, Taylor sostiene que las deliberaciones acerca de nuestros propósitos y virtudes se encuentran ineludiblemente relacionadas con las consideraciones en torno a lo que somos qua seres humanos. De esto se sigue que las cuestiones morales se encuentran estrechamente conectadas con las teorías de la motivación humana. Esto, a su vez, significa que no es admisible establecer una demarcación estricta entre las cuestiones relativas a la realización personal, por un lado, y las consideraciones acerca de la verdad o la corrección universal, por el otro. Insistir en ello, nos dice Taylor, no hacemos más que abrir la puerta al subjetivismo, como ha elegido una importante corriente de la modernidad. Eso no significa que Habermas desconozca las cuestiones referidas a la autoexpresión, a la autenticidad. Habermas reconoce al arte moderno como una esfera diferenciada de la racionalidad de nuestra época, junto a la moral-práctica y la cognitiva instrumental. Sin embargo, señala Taylor, lo que no puede encajar en su esquema es "la búsqueda de las fuentes morales fuera del sujeto a través de 
los lenguajes que resuenan dentro de él, la captación de un orden que va inseparablemente catalogado con la visión personal" (Taylor, 1989, p. 510).

Esto se debe, fundamentalmente, a la propia concepción de modernidad a la que se adscribe Habermas. Porque pese a que reconoce un sentido premoderno en el que el anthropos era parte de un orden superior, el desarrollo de la racionalidad moderna muestra, según él, la incoherencia de esa visión, puesto que el propio proceso de diferenciación hace insostenible el antiguo sentido de orden. Dice Taylor:

\begin{abstract}
Ahora pueden existir: (1) Un intento científico de conocer el mundo objetivado, es decir, ya no es visto en términos de su significado para nosotros. (2) El intento de la razón práctica de determinar el derecho. (3) Las exploraciones de la integridad y la autenticidad subjetivas expresivas. Pero no existe un lugar coherente para la exploración del orden en que nos hallamos como lugar de las fuentes morales, lo que Rilke, Pound, Lawrence y Mann hicieron de formas radicalmente diferentes (Taylor, 1989, p. 510).
\end{abstract}

En estos casos, nos dice Taylor, la exploración no es de un orden "objetivo", en el sentido clásico del término, es decir, una realidad públicamente accesible. Aquí de lo que se trata es de un orden al cual sólo es posible acceder a través de la resonancia personal, subjetivamente. Pero a diferencia de las tendencias subjetivistas que se deslizan hacia una autocelebración de las facultades o hacia la localización de las fuentes de la liberación en nosotros mismos, aquí se trata de una empresa cuyo intento es precisamente la superación del subjetivismo.

De esto se sigue que la racionalidad, como principio ético fundamental, debe ser suplementada, o un concepto más extenso de la racionalidad debe ser introducido. Un concepto que incluya criterios substancialista de la razón. En breve:

Una teoría del discurso del lenguaje tiene enormes y beneficiosas consecuencias para una teoría de la sociedad en términos teoréticos y político-morales. Sin embargo, las ventajas se pierden parcialmente al optar por una ética procedimental y la distinción que ésta implica entre tres dimensiones lógicas independientes de la racionalidad. Como resultado, la noción de razón práctica es distorsionada; en particular, el rol central que juega el lenguaje como medio para revelar nuevos terrenos que permanecen ocultos. El lenguaje 
como tal es situado en un dominio independiente de la racionalidad: en su dimensión expresiva sólo sirve como conocimiento de sí y representación del sí, y no contribuye en nada a la determinación de lo que es normativamente correcto (Taylor, 1991, p. 34).

\section{Referencias}

Bell, D. (1976). The Cultural Contradictions of Capitalism . New York: Basic Books.

Dallmayr, F. (1996). The Discourse of Modernity: Hegel, Nietzsche, Heidegger and Habermas. En M. Passerin D'entrèves, \& S. Benhabib, Habermas and the Unfinished Project of Modernity. Cambridge U.K.: Polity Press.

Habermas, J. (1988). Ensayos políticos. Barcelona: Península.

Habermas, J. (2001). Teoría de la acción comunicativa, I. Racionalidad de la acción y racionalización social. Madrid: Taurus.

Habermas, J. (2001). Teoría de la acción comunicativa, II. Crítica de la razón funcionalista. Madrid: Taurus.

Habermas, J. (2008). El discurso filosófico de la modernidad. Buenos Aires: Katz Editores.

Passerin D'entrevès, M. (1996). Introduction. En M. Passerin D'entrèves, \& S. Benhabib, Habermas and the Unfinished Project of Modernity. Cambridge UK: Polity.

Taylor, C. (1989). Sources of the Self. The Making of Modern Identity. Cambridge M.A.: Cambridge University Press.

Taylor, C. (1991). Language and Society. En A. Honneth, \& H. Joas, Communicative Action. Essays on Jürgen Habermas' Theory of Communicative Action. Cambridge M.A.: MIT Press. 